\title{
Knowledge and Attitude of Population Towards Iodized Salt in Shendi Locality River Nile State in Sudan
}

\author{
Ahmed Elnadif Ahmed Elmanssury \\ Department of Public Health, Faculty of Public Health and Health \\ Informatics, Qassim University, KSA \\ Safa Abdalla Elnour \\ Department of Epidemiology, Ministry of Health, Kordufan North State, \\ Sudan \\ Yousif Mohammed Ahmed Elmosaad \\ Department of Public Health, Faculty of Public Health and Health \\ Informatics, Qassim University, KSA
}

URL:http://dx.doi.org/10.19044/esj.2017.v13n6p312

\begin{abstract}
Background: Iodine is observed as one of the most important trace elements in the human body, which is considered very essential during the synthesis of thyroid hormones. Iodine deficiency in humans can cause several diseases or problems, which include spontaneous abortion, increased infant mortality, cretinism, goiter, and mental defects.

Methods: The study was conducted as a community based descriptive crosssectional study to determine the knowledge and attitude of the population towards iodized salt in Shendi locality, River Nile State, Sudan, during the period of 2013. In this study, 636 households were included. Questionnaire and observations were used as tools for data collection. The households were selected through a multistage cluster-sampling technique, 636 respondents were selected through systemic random sampling.

Results: The study found that the knowledge of the respondents about iodized salt was poor. Out of 636 subjects, $356(56 \%)$ were aware of iodine as a nutritional element. 279 (43.9\%) identified that iodine is a chemical element. More than half of the respondents, 355(55.8\%), were aware of sources of iodine in foods. The data showed that $299(47 \%)$ of the respondents were aware of the main type of food which contains iodine. 356(56\%) were aware of the fact that iodine deficiency had significant influence on the body. In addition, study revealed that 261(41\%) of participant were aware of iodized salt. Only $48 \%$ of the population knew that iodized salt is necessary to alleviate iodine deficiency disorder.
\end{abstract}


Conclusion: Based on our findings, we conclude that the household has poor knowledge, negative attitude, and poor practice about iodized salt. Hence, health authority should have to develop health education programs to increase the awareness of households about the significance of iodized salt. Also, it involves a proper handling of a continual and effective use of media for broadcasting health education programs.

Keywords: Iodine, Knowledge, Attitude, iodized salt, Iodine deficiency disorder

\section{Introduction}

Iodine is an essential component of the thyroid hormones that play an important role in human development, growth, and metabolism, especially on the brain. Iodine deficiency in humans can cause several diseases or problems, which include spontaneous abortion, increased infant mortality, cretinism, goiter, and mental defects. Seawater is a huge reservoir of iodine. One of the major pathways for the entry of iodine into the human food chain involves the transfer of iodine from the sea to the atmosphere, its subsequent deposition into the soil, and incorporation into plants and animals. Kelp, a type of macro algae in the ocean, is a rich source of iodine and is thus used as a food and nutritional supplement.

Iodine atoms are involved in atmospheric ozone depletion and aerosol formation reactions in the marine boundary layer. Therefore, it has a significant influence on the earth's radiative balance and weather, which in turn may affect human health ( $\mathrm{Li}$, et al., 2009).

Iodine deficiency, through its effects on the developing brain, has condemned millions of people to a life of few prospects and continued underdevelopment. On a worldwide basis, iodine deficiency is the single most important preventable cause of brain damage. IDDs are among the easiest and cheapest of all disorders to prevent. The everyday use of a small and constant amount of iodine contained in the salt is all that is needed (WHO, 2000).

Public awareness and publicity is also necessary so that there is a demand for iodized salt. In the case of a dual market (both iodized and noniodized salts available), it is necessary to make the public aware and raise such a demand. Once the iodization of salt for human use becomes mandatory, periodic public education for proper storage and usage of iodized salt should continue. Consumers have to be convinced of the importance of iodine to their health. Therefore, people's knowledge about goiter and other less obvious manifestations of IDD were addressed in educational strategies (Azizi, 2009).

Ideally, salt iodization programs ensure that there is adequate iodine intake for the entire population. Also, the cost of iodization is included as part 
of the cost of doing business within the salt industry. The IDD program in this case simply needs to monitor the situation.

In reality, even with mature salt iodization programs with high coverage, the programs remain vulnerable to changes in the salt industry, changes in political will, and changes in awareness or consumer acceptance. Thus, it is important to monitor the overall programmatic indicators as well as measures of salt iodization and impact to ensure that its achievements are sustained (WHO, 2007).

\section{Methods}

Shendi is one of River Nile State. It is bounded by Khartoum state in the south, Elddamer locality to the north, River Nile to the west, and Gadarif state to the east. The locality area is about $14596 \mathrm{Km}^{2}$. The rural areas of the Shendi locality are composed of about 96 villages, and 63 of them are at the southern side of the locality. Topographically, the locality lies on a flat mudsandy area adjacent to the River Nile with a few scattered mountains in the eastern part and is accessible all the year. Geographically, it lies between line $36^{\circ}$ East to $31^{\circ}$ West longitude and line $19^{\circ}$ North to line $15^{\circ}$ South latitude in the arid zone of Sudan with an annual rainfall ranging between 0 and 119/ml per year. It is situated on the main River Nile, which is the source of water for the agriculture. Its main cash crops are white beans, onions, wheat, and sorghum. Goats and camels are owned both by the few nomadic 'Rashaida' and the settled farmers.

Culturally, the population of Shendi is a mixture of the various cultures that occur in Sudan though the Northern tribes, particularly ElGaalien, are predominant. The population of Shendi locality is estimated to be about 2,69, 446. About $60 \%$ of the population is rated as poor and it has the following statistics: Growth Rate 2.3\%, Males 48.7\%, and Females 51.3\%. In addition, the average family size is 6 members. $78 \%$ of the population depends on agriculture, while the rest are traders, teachers, and handicraft workers, including spinners, weavers, and other artisans.

\section{Study Design}

It was a community based on a descriptive cross-sectional study carried out to study the knowledge and attitude of the population towards iodized salt in Shendi locality, River Nile State.

\section{Sample Size}

The sample size was determined for the study area using the formula for cluster survey $\left(n=z^{2 *} p^{*} q / d^{2} *\right.$ deff $)$. It was calculated on the basis of the prevalence of $50 \%$ and a design effect of 1.5 . 
The multistage cluster sampling technique was followed for the selection of the study population in three stages. Firstly, the locality was divided into four administrative units. Also, the three clusters were selected using the probability proportional to size (PPS) sampling method. Secondly, all administrative units were divided into cluster villages or block (cluster sampling technique). A random sampling technique was then used on any relevant clusters to choose which villages or block to include in the study in each identified cluster. Thirdly, all households of the selected cluster was enlisted. An attempt was made to select an equal number of households in the unit as far as possible.

The required number of households in each village and block was selected by following the systemic random sampling technique. The sample size was distributed for each village using the following formula: $K=N / n$, Where: $\mathbf{K}=$ interval, $\mathrm{N}=$ population, and $\mathrm{n}=$ sample.

\section{Statistical Analysis}

After the data was collected, they were coded and transferred into specially designed formats to be suitable for computer feeding. In the analysis, scores were given to each questions related to knowledge and attitude respectively. The participants who scored above the mean for knowledge questions were considered as having good knowledge, while others (below mean level) were considered as having poor knowledge. Similarly, subjects who scored above the mean for questions related to attitude were considered as having positive attitude, while others (below mean level) were considered as having negative attitude. The answer sheet was checked for completeness and the data were entered on the Statistical Package for the Social Sciences (SPSS version 11.5) for analysis.

\section{Results}

Table 1. Distribution of demographic characteristics of the respondents in shendi locality

\begin{tabular}{|c|c|c|c|}
\hline & Characteristics & Frequency & Percentage \\
\hline \multirow{4}{*}{1} & Household occupation & & \\
& Farmer & 188 & 29,6 \\
& Laborer & 258 & 40,6 \\
& Employee & 127 & 20,0 \\
& Unemployment & 63 & 9,9 \\
\hline \multirow{4}{*}{2} & Monthly income & & 41.0 \\
& Less than 500 pound & 261 & 48.0 \\
& 500- 1000 pound & 305 & 11.0 \\
\hline
\end{tabular}




\begin{tabular}{|c|c|c|c|}
\hline \multirow{4}{*}{3} & Level of education & & \\
& Illiterate & 111 & 17.4 \\
& Informal & 85 & 13.4 \\
& Formal & 440 & 69.2 \\
\hline \multirow{4}{*}{4} & Family number & & \\
& Less than 6 & 364 & 57.2 \\
& 6-9 & 222 & 34.9 \\
& Above 9 & 50 & 7.9 \\
\hline
\end{tabular}

Consequently, socio-demographic information on the study population is presented in Table 1. A total of 636 households were included during the study. $258(40.6 \%)$ of the respondents were laborer and $(9.9 \%)$ have no specific occupation. As shown in Table 1, 305 (48.0\%) of the participant's income (according to product method) were about 500-1000 pounds. Educational status of the respondents are 440 (69.2\%) formal education, $111(17,4 \%)$ illiterate, and $85(13.4 \%)$ informal education. The study showed that the family size varies. The category (less than six) represents half of the population $364(56.2 \%)$, while the category (above 9) has the lowest frequency 50 (7.9\%).

Table 2. Responses to the questions on the knowledge level of respondents towards iodized salt

\begin{tabular}{|c|c|c|c|}
\hline \multirow{2}{*}{ Id } & Knowledge regarding iodine and iodized salt & \multicolumn{2}{|c|}{ Correct answer $(\mathrm{n}=636)$} \\
\cline { 3 - 4 } & & $\mathrm{n}$ & $\%$ \\
\hline 1 & Knowledge of iodine & 356 & 56.0 \\
\hline 2 & Identification of iodine & 279 & 43.9 \\
\hline 3 & Sources of iodine & 355 & 55.8 \\
\hline 4 & Knowledge of food contain iodine & 299 & 47.0 \\
\hline 5 & Types of food that contains iodine & 298 & 46.9 \\
\hline 6 & Awareness of iodine deficiency disorder & 356 & 56.0 \\
\hline 7 & Awareness of iodized salt & 261 & 41.0 \\
\hline
\end{tabular}

Altogether, 636 of the population responded to the questionnaire. The answers given by them were summarized in Table 2. Out of 636 subjects, 356 $(56 \%)$ were aware of iodine. $279(43.9 \%)$ identified that iodine is a chemical element. More than half of respondents 355(55.8\%) were aware of the various sources of iodine. The data showed that 299 (47\%) of the respondents were aware of foods that contain iodine and its types. 356(56\%) were aware of the fact that iodine deficiency had significant influence on the body and knew that it causes goiter. Also, study revealed that 261(41\%) of participants were aware of iodized salt. 
Table 3. Association between potential demographic factors and knowledge regarding

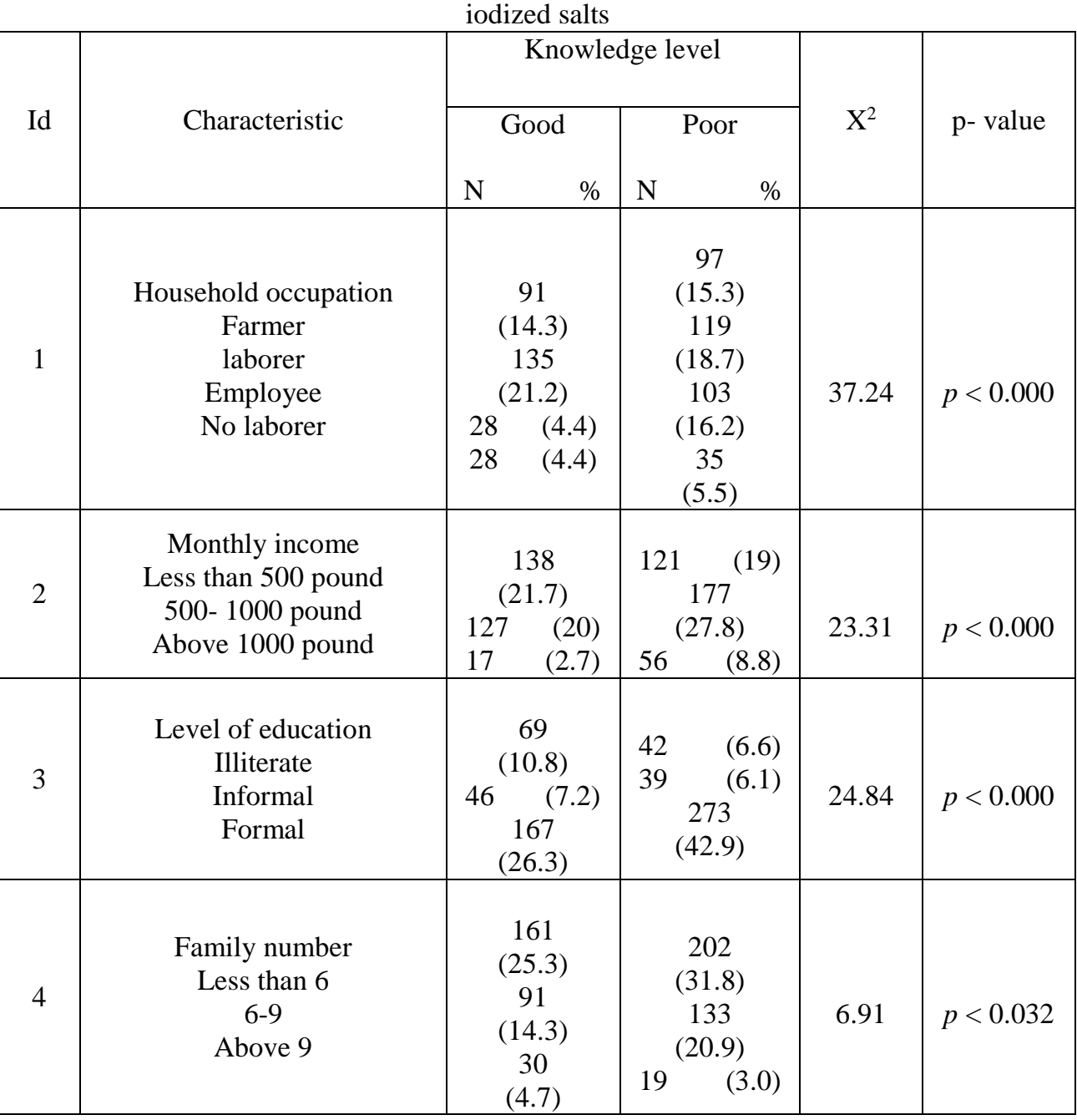

The level of knowledge was compared with socio-demographic status of the study subjects and it was presented in Table 3 . The study demonstrates that knowledge was effected with socio-demographic. Data showed that about forty percent belonged to the respondents with the occupation of laborer. Nearly fifty percent of the participants have an income between $500-100$ pounds. More than sixty-nine percent of the respondents had formal education level. Moreover, most of the respondent's family size is less than six persons. The level of knowledge showed significant associations with Household occupation $\left(\mathrm{X}^{2}=37.24 . p<0.000\right)$, Monthly income $\left(\mathrm{X}^{2}=23.31 . p<0.000\right)$, Level of education $\left(X^{2}=24.84 . p<0.000\right)$, and Family number $\left(X^{2}=6.91\right.$. $p<0.032$ ). 
Figure 1. Attitude of respondents about the availability of adequate iodized salts

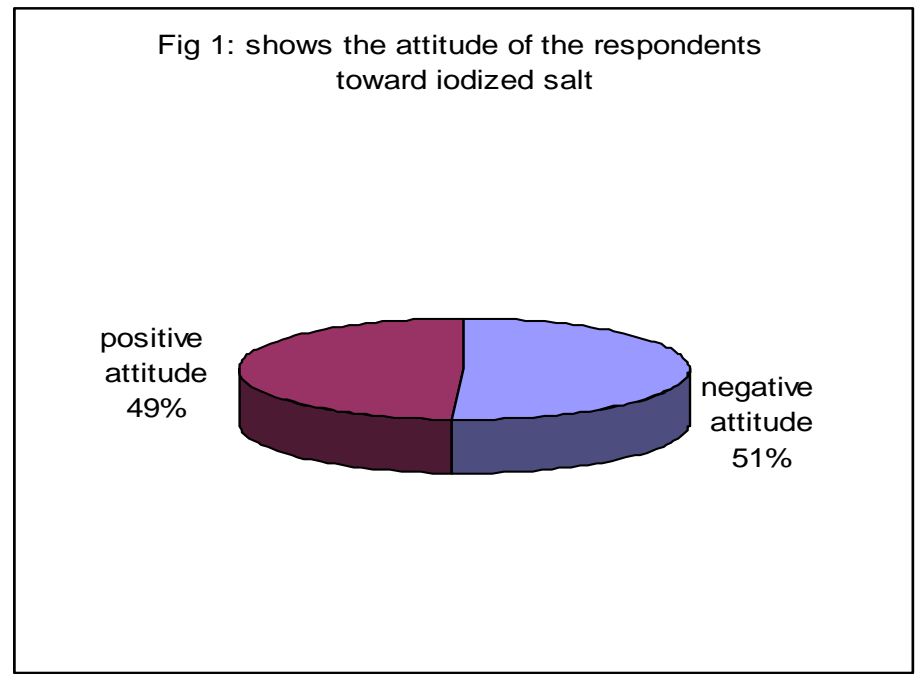

The answers of the respondents with regards to the Attitude question are indicated in Figure 1. As given in Figure 1, 49\% of the respondents indicated positive attitude, while $51 \%$ of them shows negative attitude.

Table 4. Socio- demographic characteristic with Attitude of respondents towards iodized salts

\begin{tabular}{|c|c|c|c|c|c|c|c|}
\hline \multirow{3}{*}{ Id } & \multirow{3}{*}{ Characteristic } & \multicolumn{4}{|c|}{ Attitude } & \multirow{3}{*}{$\mathrm{X}^{2}$} & \multirow{3}{*}{ p- value } \\
\hline & & \multicolumn{2}{|c|}{ Negative } & \multicolumn{2}{|c|}{ Positive } & & \\
\hline & & $\mathrm{N}$ & $\%$ & $\mathrm{~N}$ & $\%$ & & \\
\hline 1 & $\begin{array}{c}\text { Household occupation } \\
\text { Farmer } \\
\text { Employee } \\
\text { Provisional } \\
\text { Other }\end{array}$ & $\begin{array}{l}(15.9) \\
(21.9) \\
(6.8) \\
(6.3)\end{array}$ & $\begin{array}{c}101 \\
139 \\
43 \\
40\end{array}$ & $\begin{array}{l}(13.7) \\
(18.1) \\
(13.8) \\
(3.6)\end{array}$ & $\begin{array}{c}87 \\
115 \\
88 \\
23\end{array}$ & 23.20 & $\begin{array}{c}p< \\
0.000\end{array}$ \\
\hline 2 & $\begin{array}{l}\text { Monthly income } \\
\text { Less than } 500 \text { pound } \\
500-1000 \text { pound } \\
\text { Above } 1000 \text { pound }\end{array}$ & $\begin{array}{c}(24.7) \\
(22.8) \\
(3.3)\end{array}$ & $\begin{array}{c}157 \\
145 \\
21\end{array}$ & $\begin{array}{c}(16.0) \\
(25.0) \\
(8.2)\end{array}$ & $\begin{array}{c}102 \\
159 \\
52\end{array}$ & 25.33 & $\begin{array}{c}p< \\
0.000\end{array}$ \\
\hline 3 & $\begin{array}{l}\text { Level of education } \\
\text { Illiterate } \\
\text { Informal } \\
\text { Formal }\end{array}$ & $\begin{array}{c}(11.6) \\
(7.9) \\
(31.3)\end{array}$ & $\begin{array}{c}74 \\
50 \\
199\end{array}$ & $\begin{array}{c}(5.8) \\
(5.5) \\
(37.9)\end{array}$ & $\begin{array}{c}37 \\
35 \\
241\end{array}$ & 18.83 & $\begin{array}{c}p< \\
0.000\end{array}$ \\
\hline 4 & $\begin{array}{c}\text { Family number } \\
\text { Less than } 6 \\
6-9 \\
\text { Above } 9\end{array}$ & $\begin{array}{c}(28.1) \\
(17.6) \\
(5.0)\end{array}$ & $\begin{array}{c}179 \\
112 \\
32\end{array}$ & $\begin{array}{c}(28.9) \\
(17.6) \\
(2.7)\end{array}$ & $\begin{array}{c}184 \\
112 \\
17\end{array}$ & 4.50 & $\begin{array}{c}p< \\
0.105\end{array}$ \\
\hline
\end{tabular}


Consequently, analysis was done by comparing the attitude on iodized salt opinion, with deferent socio-demographic characteristic of the population. In Table 4, there was a significant association with Household occupation $\left(\mathrm{X}^{2}\right.$ $=23.20 . p<0.000)$, family income $\left(\mathrm{X}^{2}=25.33 . p<0.000\right)$, and Level of education $\left(\mathrm{X}^{2}=18.83 . p<0.000\right)$. Thus, the study showed that there are no significant association with family number $\left(\mathrm{X}^{2}=64.50 . p<0.105\right)$.

\section{Discussion}

Findings regarding knowledge in the present study suggest that $56 \%$ of the respondents indicated that they have heard about iodine, deficiency of iodine in the environment, and the insufficient intake of iodine into the human body. This shows that the public awareness about iodine is not sufficient. Sebotsa et al in Free State South Africa showed that majority of the patients $(86.9 \%)$ indicated that they did not know what iodine is. Even those who mentioned that they knew what it was $(14.1 \%)$ were not clear. This was because $4.9 \%$ indicated that it is a vitamin, while $4.9 \%$ indicated that it is a mineral (Sebosta et al., 2009). Abu Sabeeb, et al reported that $24 \%$ of the students did not know what iodine is (Abusabeeb et al., 2013). However, this is in agreement with our study.

Furthermore, our study showed that around half of the respondents (47\%) have knowledge of food that contains iodine. This was conceded as poor knowledge. Charlton et al reported similar findings that dairy foods were the highest contributors to dietary iodine intake (57\%-62\%). A low intake of fish and seafood resulted in this food group that contributes only to $3 \%-8 \%$ of total intake (Charlton et al., 2010).

More than half of the population $(55 \%)$ in our study has knowledge about the sources of iodine. Charlton, et al in the study that was conducted in Australian women reported that knowledge of dietary sources of iodine was also found to be poor, (Sebosta et al., 2009). Jooste, et al showed that only $15.4 \%$ of the respondents correctly identified iodized salt as the primary dietary source of iodine (Jooste, et al., 2005). Sebotsa et al showed that based on the knowledge on the main source of iodine in food consumed by the people in South Africa, a higher percentage of patients (76.7\%) lacked the knowledge of iodine (Sebosta et al., 2009). A study conducted by Charlton et al in Australia reported that poor knowledge about the role and sources of iodine in the diet remained after fortification (Sebosta et al., 2009).

Therefore, the result of our study show that more than half of the respondent $(56 \%)$ have knowledge about iodine deficiency disorder. Niksic et al reported that only half of the participants (49.1\%) know of iodine deficiency disorder (Niksic et al., 2006). Umenwanne, et al showed that Less than $15 \%$ of the respondents could link goiter to iodine deficiency (Umenwanne et al., 2000). 
Iodized salt is the main sources of dietary iodine in Sudan population, and it has been the main strategy to control the iodine deficiency disorder. In our study, less than half of the respondents (41\%) correctly answered about the knowledge of iodized salt. This finding showed poor knowledge in agreement with the study conducted by DeZoysa, et al which reported that $40 \%$ of respondent had poor knowledge on iodized salts and the importance of iodine in diet (DeZoysa et al., 2015). Buxton et al found that the knowledge of iodized salt was quite high, as $72 \%$ of the respondents knew that not every salt contains iodine (Buxton et al., 2012). The study conducted by Gerensea $e t$ $a l$ in Hawelti Kebelle shows that majority (94\%) of the respondents have heard about iodized salt (Gerensea et al., 2015). Gidey, et al showed that the availability of adequate iodized salt was low, and attending formal education makes it easier to have a good knowledge about iodized salt and iodine deficiency disorders (Gidey, et al., 2015).

\section{Conclusion}

Based on our findings, we conclude that those households have poor knowledge and a negative attitude towards iodized salt. Hence, households should be informed about the significance of iodized salt and its proper handling. Also, there should be a continual and an effective use of the media for broadcasting health education programs.

\section{Acknowledgments}

The authors are grateful to all heads of households who gave the researchers the permission to interview respondents. We are also grateful to the people who supported the study and offered various helpful advice and inputs, especially during the data collection phase of the study.

\section{References:}

1. Abu Sabeeb Z, and Dr. Ali HA. (2014). Assessing the Elimination of Iodine Deficiency Disorder in Al ShaabiahBahri/ Khartoum State/ Sudan, International Journal of Science and Research, Volume 3 Issue 12, Pp: 1147-1152.

2. Azizi, F, (2009). Thyroid International, $4^{\text {th }}$ edition, publication Merck KGaA, Darmstadt, Germany.

3. Buxton and Baguune (2012). Knowledge and practices of people in Bia District, Ghana, with regard to iodine deficiency disorders and intake of iodized salt. Archives of Public Health 70:5. 
4. Charlton K E, Heather R Y, \& Fiona H. (2010). Poor iodine status and knowledge related to iodine on the eve of mandatory iodine fortification in Australia. Asia Pac J Clin Nutr;19 (2):250-255.

5. Charlton K, Heather Y, Catherine L, Samantha A, Luke G, Fiona H, Alison G, and Gary M. (2012). Poor Knowledge and Practices Related to Iodine Nutrition during Pregnancy and Lactation in Australian Women: Pre- and Post-Iodine Fortification. www.mdpi.com/journal/nutrients. Nutrients, 4, 1317-1327; doi: 10.3390/nu4091317.

6. De Zoysa GED, Hettirachchi M, Jayathilaka KAPW, and Layange KDCA (2015). Knowledge and practice of iodized salt consumption among pregnant women in Galle District.Galle Medical journal, Vol 20: No.1.pp 10-16.

7. Gerensea H, Yohannse A, Baymot B, Atsbha H, Nguse K, Gebru L, and G/kel S. (2016). Knowledge, attitude and practice (KAP) towards iodized salt utilization in Hawelti Kebelle, Axum, Tigray, Ethiopia, Edorium J Pathol; 2:1-8.

8. Gidey B, Alemu K, Atnafu A, Kifle M, Tefera Y and Sharma HR. (2015). Availability of Adequate Iodized Salt at Household Level and Associated Factors in Rural Communities in Laelay Maychew District, Northern Ethiopia: A Cross Sectional Study. Journal of Nutrition and Health Sciences. Volume 2, Issue 1: pp; 1-9.

9. Jooste PL, Upson N, Charlton KE (2009). Knowledge of iodine nutrition in the South African adult population. Public Health Nutrition: 8(4), 382-386.

10. Li, B, H, (2009). Comprehensive Handbook of Iodine, nutritional, biochemical, pathological and therapeutic aspects. $11^{\text {th }}$ edition, academic press publication.

11. Niksic D, Kulic A C, Mujcic A K, Bajraktarevic S, and Niksic H ( 2006). Iodized salt for all. Medicine and Biology Vol.13, No 1. pp. 49 $-53$

12. Sebotsa MLD, a Dannhauser A, b Mollentze WF , b Oosthuizen GM , c Mahomed FA, d Jooste PL. (2009). Knowledge, attitudes and practices regarding iodine among patients with hyperthyroidism in the Free State, South Africa. S Afr J Clin Nutr;22 (1):18-21. 
13. Umenwanne E O and Akinyele I O. (2000). Inadequate salt iodization and poor knowledge, attitudes, and practices regarding iodinedeficiency disorders in an area of endemic goiter in south-eastern Nigeria. Food and Nutrition Bulletin, vol. 21, No. 3, the United Nations University pp: 311-315.

14. WHO (2000). Assessment and Monitoring of Iodine Deficiency Disorders in Countries of the Eastern Mediterranean Region: Report of a Symposium Workshop, WHO Regional Office for the Eastern Mediterranean, Alexandria-Egypt.

15. World Health Organization/International Council for the Control of the Iodine Deficiency Disorders/United Nations Childrens Fund (WHO/ICCIDD/UNICEF).(2007). Assessment of the iodine deficiency disorders and monitoring their elimination. a guide for programme managers. - 3rd ed, WHO. 